\title{
Research About China's Electricity Market Reform Based on Hall's Three Dimensions Structure Model
}

\author{
Jun Dong, Rong Li \\ School of Economics and Management, North China Electric Power University, Beijing, China
}

Email address:

lirong_huadian@163.com (Li Rong)

To cite this article:

Jun Dong, Rong Li. Research About China's Electricity Market Reform Based on Hall's Three Dimensions Structure Model. American Journal of Electrical Power and Energy Systems. Vol. 4, No. 4, 2015, pp. 51-56. doi: 10.11648/j.epes.20150404.14

\begin{abstract}
To promote the development of the national economy, how to improve the electricity market and establish effective competition mechanisms becomes the focus of the new round of electricity market reform in China. Referring to the basic thoughts of Hall's three dimensions structure theory of system engineering discipline, and analyzing from three levels of logic dimension, time dimension and knowledge dimension, this paper provides recommends on the implementation of electricity market reform in China. Through the compared analysis of two reform programs in the logic dimension, we obtain the modified electricity reform program for current China that is keeping the grid company having the whole business of transmission and distribution, establishing electricity sale companies, establishing power trading center and promoting power direct trading.
\end{abstract}

Keywords: Hall's Three Dimensions Structure, Electricity Market Reform, Implement Suggestion

\section{Introduction}

Electricity industry as the basic pillar industry of the national economy, whether it can keep healthy, orderly and efficient development gets much attention from the national Government and various parties. Electricity system reforms in China started from the 70's of the last century which have been trying to establish an electricity market suitable to China's national conditions and economic development. The reforms have experienced several key points [1]: During 1978-1985, when the national Governments implemented the policy of "Funding to establish plants", the electricity industry pioneered to use the bank loans in order to broaden the channels of funding and began to cultivate the market pricing mechanism. During 1987-1998, the electricity industry was separated from the Governments, and the electricity industry ministry was withdrawn with the establishment of the national power company. In 2002, the State Council issued the "Fifth Document", and started the electricity reform. The former State power grid company was split into two major power grid companies, five major power generating groups and four auxiliary groups. In 2003, the State Electricity Regulatory Commission was set up to achieve "Separating Government and Supervision"; then the "Electricity Price Reform Scheme" enacted by the State Council divided the electricity price into four forms including Internet access price, transmission price, distribution and sales price. In 2004, the National Development and Reform Commission issued the "Provisional management approaches of direct power-purchase pilots between electricity users and power generation enterprises", as well as the "Views on the establishment of coal-electricity price linkage mechanism". In 2010, as there were many controversies in the verification of transmission and distribution prices and direct power purchase for high energy-consuming enterprises and so on, several Central Government ministries stopped the local "direct purchase" pilots. First half of 2014, more than 10 provinces such as Anhui, Jiangsu, Jiangxi reset "direct purchase" pilots, and in November, the "pilot reform program for Shenzhen power transmission and distribution price" issued by the National Development and Reform Commission launched a new round of transmission and distribution price reform. In March 2015, the CPC Central Committee and the State Council promulgated the electricity reform "Ninth File"- "Some opinions on further deepening the reform of 
electricity system" ([2015]9), which officially opened the second round reform of electricity market.

The existing studies on the electricity market reform in China are mainly focused on the design of electricity market patterns and the selection of reform programs. Yao Jiangang discusses the models suitable to China's electricity market, and proposes the "contracts and spot market" form is the best way to address the problems of interests of all parties in the reform [2]. Shang Jincheng and $\mathrm{Fu}$ Shuguo propose the related reform models of electricity market by analyzing a regional power market from transaction types, market structures, competitive modes as well as function divisions, combined with the demand of electricity market development in China[3-4]. By discussing a series of changes of pricing mechanisms in China, Lin Boqiang proposes the concentration of state-owned enterprises are the root of many fundamental problems of the power industry, and points out that a successful reform program must fully take into account electricity prices, coal prices, state-owned enterprises, energy agencies and other supporting reforms[5]. Song Xiaosong and Zhang Jianhua, who analyze the kinds of power market operation modes and status of electricity system reform in China, present a gradual reforming program for China's power market[6]. Li Han and $\mathrm{Li}$ Guoren by comparing the electricity industry reform processes of United Kingdom, the United States and Japan, propose that rationally determining the price formation mechanisms is the key to the success of China's electricity market reform[7]. Chen Weiyong proposes the bilateral trading and centralized trading patterns for large purchasing users, and two approaches for cross-subsidies, including users paying additional fees and taking into account transmission and distribution fees[8]. However, these existing studies are still confined to one or two aspects of designing or researching the electricity market, but not from a system perspective to comprehensively study how to select and implement a reform program. But it is a systemic project to set up a sound and orderly electricity market involving various aspects. Thus this paper uses one of the classical system engineering theories-Hall's three dimensions structure-to systematically and comprehensively analyze the selection and implement of new round of electricity market reform in China from time dimension, logical dimension as well as knowledge dimension, and then puts forward related suggestions, based on combing the past several rounds of changes in China.

\section{Hall's Three Dimensions Structure}

Hall's three dimensions structure is a system engineering methodology proposed by United States engineering expert A.D. Hall in 1969, which provides a systematic thinking method for planning, organization, management of large and complex systems, and has been widely used all over the world. Hall's three dimensions structure divides a whole system engineering process into 7 stages and 7 steps closely linked with each other, and meanwhile it also considers various required professional knowledge and skills for the completion of these phases and steps. The structure is formed by three dimensional space structure including time, logic and knowledge dimension [9]. Among them, the time dimension represents the whole process of system engineering activities from start to finish according to the chronological order, which is divided into 7 time stages including planning, programming, development, production, installation, operation, updating. Logical dimension refers to the work contents and thought process that should be followed during each time stages, including defining the problem, identifying the objectives, system integration, system analysis, system optimization, decision and implementation, these 7 logical steps. Knowledge dimension means those required knowledge synthesis when solving complex problems, including engineering, medicine, architecture, business, law, management, social sciences, arts and other knowledge and skills. The three dimensions structure vividly describes the framework of system engineering, and each step at any stage can be further expanded, finally forming a hierarchical structure system.

This paper refers to the thoughts of Hall's three dimensions structure theory, from the perspective of the time dimension to analyze the key steps of an electricity reform program implementation, from the viewpoint of the logical dimension to propose and verify a viable power market reform program, from the perspective of knowledge to analyze the conditions required before and in the process of program implementation.

\section{Application of Hall's Three Dimensions Structure in the Electricity Market Reform}

\subsection{Logical Dimension}

\subsubsection{Defining the Problem}

In the previous round of reform launched in 2002, despite the fact that the separations of governments and enterprises, plants and grids, main and auxiliary service, have been achieved, the "transmission and distribution separated" and "bidding on grid" these two major reforms identified in the file have been stalled for a long time. In order to realize the strategic goals proposed in the eighteenth National Congress of the CPC which is "By 2020, GDP and income of urban and rural residents are more than quadrupled than 2010 ", electricity as a fundamental industry must be first developed towards a higher level. But China's current power market at generation side and sale side does not form a good competitive environment and both the electricity on-grid price and sale price do not realize the goals set by the 
market reform. How to form a competitive pricing mechanism is the next important issue faced by the electricity reform.

\subsubsection{Identifying the Objectives}

The Grid company's monopoly in transmission-distribution and scheduling is the key factor hindering market-oriented pricing. In order to stimulate the enthusiasm of electricity consumers, market competition in sale side need to be brought in firstly to break the status quo that users can only purchase electricity from the grid companies and then a number of alternative electricity sale sources should be provided, so as to establish competition mechanisms of the sale price.

\subsubsection{Forming System Schemes}

Reform for the electricity sale side mainly has two executable programs. One is based on the "Fifth File" goals, "transmission and distribution separated" and "bidding on grid", to continue to deepen power market reform. Separate the transmission and distribution business of grid companies; establish more than one distribution companies and electricity sale companies, and achieve power generating enterprises bidding on grid. Another program is not to split the transmission and distribution business of grid companies, but to stripping their part of the electricity sale business, that is to say based on the former big users' electricity straight purchase pilots, further form the power direct transaction model.

\subsubsection{Schemes Analysis}

The first scheme mainly contains the contents that split the Grid companies' transmission and distribution business; establish independent distribution companies, opening distribution side and allowing social capital access into new distribution network; set up independent electricity companies, allowing private capital to enter. These measures, in theory, can effectively break the Grid company's monopoly whose profit mode will also turn from benefiting from price differentials between on-grid electricity price and sales price to charging net wheeling fees. For the second scheme, it ensures the integrity of the companies' transmission and distribution business, only spinning off their electricity sales business, and allowing the user to directly purchase electricity from electricity trading and generation companies. The grid corporations only charge net-using fees authorized by the Government during consumers directly dealing with the power generators. Compared to the previous large consumers' direct-purchasing, electricity direct trading mode emphasizes more on the user's own option, allowing users and generation companies trading on a unified platform. It realizes generators bidding to sale electricity and users can select with more choices or bidding to purchase, which will gradually achieve the market prices rather than the Government price. From the analyses of program one and program two, it can be found that the main difference between the two is that whether or not to separate the Grid company's transmission and distribution business and whether to set up an independent electricity companies.

\subsubsection{Schemes Evaluation}

Aimed at the points proposed in the program one that "separation of the Grid's transmission and distribution business", most experts hold a negative opinion. This paper also believes that splitting power grid pays too much, and is not conducive to the construction of China's power market. There are four main reasons: first of all, transmission and distribution functions are similar. Power transmission and distribution business both have the network properties and similar functions as the logistics behavior of electricity. Secondly, the transmission and distribution network is not easy to split. Power distribution network of $220 \mathrm{kv}$ and below at present also bears close-range transmission function, so it is difficult to precisely dividing the transmission and distribution from the assets interface. In addition, power transmission and distribution network has significant scale economies. Their huge construction costs determine the properties of natural monopoly. Finally, transmission and distribution as a whole is more conducive to power supply safety. Thus splitting the transmission and distribution is not the main point of the next reform.

Whether to set up independent electricity companies, power generation companies, Grid companies, and users hold uniform views. At the international level, this issue is also a great dispute. Texas of the United States conducted the similar reform in 2002, hoping to enhance competition in the market and lower retail prices and industrial electricity prices by bringing in independent selling companies [10]. But at last the reform effect does not achieve as expected. Its sale electricity side competition has no enhancement and electricity price is also not reduced [11]. Scholars Joskow and Jean Tirole in their articles have done demonstrations on whether electricity sale side should take complete competition. The results display that in the situation of without installation intelligent meters, market information is not complete, so social suboptimal choice will be the same as monopoly market equilibrium, that is, the competition reform of electricity sale market could reduce the whole market's efficiency instead. Competitive mechanisms may be more invalid than monopolistic mechanisms [12]. Tirole's research has a specific reference meaning, but we should also see that the conclusion is based on the transmission and distribution costs set to zero and derived under the assumption of full market monitoring. In the present electricity market in China, the practice in line with the actual is to form monopoly competition on the sales-side and then to reform gradually. Through the construction of a smart grid, smart meters installed on the user-side, the market will gradually translate to be with the full competition. 


\subsubsection{Decision}

Decision making stage is mainly based on the analysis and evaluation of the steps above, to identify an optimal solution. Through the analysis of all aspects of the two different programs, this paper argues that the electricity market reform program most suitable to current China is to keep the transmission and distribution business of grid companies as a whole, and to establish an electricity trading center, allowing direct transactions between power plants and large consumers. In addition, grid companies still keep the selling business, but they need to purchase power through the trading center.

\subsubsection{Implementation}

This stage is to implement the selected program, namely decision execution phase. The electricity reform can be implemented in pilot regions first. If the implementation is successful, then it can be revised and perfected to be promoted in the whole country. However, often there will be new problems in practice. Thus it needs to take remedial actions or tracking regulatory and continue modification and perfection, depending on the actual situation of implementation and feedback.

\subsection{Time Dimension}

This dimension refers to the 7 activity development stages of electricity market reform program from the planning stage to the improvement stage, in accordance with the order of time. It can generally be divided into the following seven stages, which are interconnected with the 7 logical stages above, with no clear line in the system.

(1) Planning phase. It is the electricity market reform program planning and preparation stage at which government departments and various stakeholders should put forward proposals for the future fast development on the basis of the full investigation, and according to their own characteristics and actual environmental situation.

(2) Programming phase. Design and propose the system structure of the electricity market reform program, including the structures of subsystems.

(3) System analysis phase. According to the concrete architecture of the program, analyze the system and from different views, study what's change and influence the reform program may bring.

(4) Pilots implementation phase. Enact the determined reform program in the pilots with a sound electricity industry, laying the foundation for the further promotion.
(5) Debugging phase. Based on the implementation results of the pilots, adjust the problems exposed during the implementation of the reform program, and then put the modified program into pilot operation again until getting the improved scheme.

(6) Promotion phase. The improve program should be promoted in regions gradually, and continue to track some important indicators of it in the implementation process, ongoing monitoring whether the reform effect achieves the design requirements.

(7) Upgrading stage. According to the new problems that have emerged in the practice of regional promoting, improve the existing program based on the views of various parties, and transform reasonable reform paths to find the reform direction that can achieved the maximum benefits of the whole community.

\subsection{Knowledge Dimension}

Electricity market reform is a complex and comprehensive process, which needs to be actualized step by step. To complete each stages and steps above, it needs extensive knowledge and expertise. Its construction and running involves the knowledge of electricity systems, law, business, management, finance, social sciences, engineering technology and other social science and natural science, and each step and stage depending on different issues will involve the different knowledge. This requires that investigate fully during the program formulation and modification process; listen to experts' opinions, and follow the macro-control laws and step-by-step implement principle.

This dimension should not only consider the expertise and technologies involved in the development of reforms, but also the necessary precedent conditions before implementing the electricity market reform program. First, relevant laws should be sound. The electricity industry, as a basic pillar industry of the whole national economy, must be introduced a series of laws as the conduct codes to guarantee the effective reform application. Second, the Government should publish related policies including pricing rules, grid transmission and distribution requirements. Finally, establish sound market supervision and trading mechanisms to ensure that the reform can be effectively implemented. Hall's three dimensions structure of the power market reform in shown in Figure 1. 


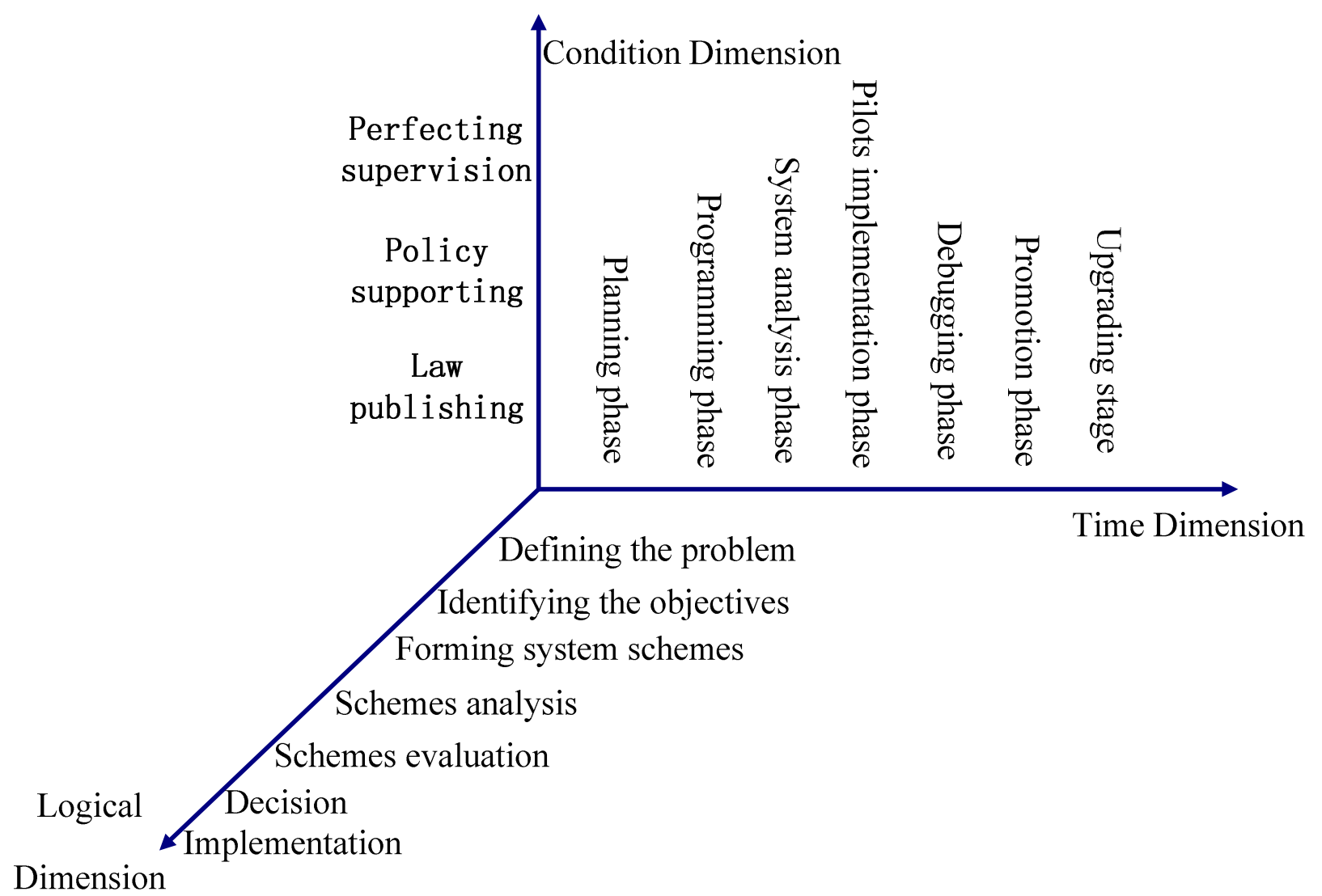

Figure 1. Hall's three dimensions structure of the power market reform.

\section{Conclusion}

Based on the theory of Hall's three dimensions structure, this paper builds an electricity market reform program adapted to the development of China. From logical dimension, time dimension and knowledge dimension, make a stepwise analysis of the planning and implementation of the reform scheme to provide a reference and guidance for policy makers and market entities about how to carry on the next step. But it should be also recognized that in theory, the logical dimension, time dimension and knowledge dimension of Hall's three dimensions structure are closely linked and interrelated, which also constructs an interacted and interdependent three-dimension structure of the power market reform as a complete system. To establish effective competition of power market should be based on the scientific planning mechanism, combine with the regional actual situations in China, and not just stuck with some theoretical dogmas. At the same time, the reform decision mechanisms should be also perfected, which needs related subjects participation and to combine the Government decision with expert arguments. Make Hall's three dimensions structure this systems engineering methodology play a real guide role in the power market reform, so as to promote the healthy, harmonious and sustainable development of China's economy and society.

\section{References}

[1] ZHOU Jun. Discussion on the Reform Issues of the Electric Power System in China[J], Journal of Guangdong Polytechnic Normal University, 2009(1):50-54.

[2] YAO Jiangang. Discussion on the structure and bidding modes of regional electricity market[J], Automation of electric power system, 2003,27(22):23-25.

[3] SHANG Jincheng, ZHANG Zhaofeng, HAN Gang. Study on transaction model and mechanism of competitive regional electricity market part one transanction model and mechanism, participation mode for hydroelectricity participants and power system security checking mechanism $[\mathrm{J}]$, Automation of electric power system, 2005,29(12):7-14.

[4] FU Shuguo, BAI Xiaomin, ZHANG yang et al. Regional electricity market mode and operation mode research[J], Automation of electric power system,2003,27(9):1-5.

[5] LIN Baiqang. The growth of China's electrical industry: the reform process, and reform that fit each other[J], Management World,2005(8):65-79.

[6] SONG Xiaosong, ZHANG Jianhua, LIU Zongqi. Analysis on the reform modes of electricity market in China[J], Electricity Education in China,2007, Management review and educational research Special Issue:245-248. 
[7] LI Guoren, LI Han. Enlightenment from Electricity Industry Reforms in UK, US and Japan[J], SINO-GLOBAL ENERGY,2009(14):21-26.

[8] CHENG Haoyong, ZHANG Senlin, ZHANG Yao. Research on transaction mode of direct power purchase by large consumers in electricity market[J], Grid Technology,2008,32(21):85-90.

[9] HALL AD. Three-dimensional morphology of system engineering [J], IEEE Transactions on System Science and Cybernetics, 1969: 5(2).
[10] HE Xueming. Electricity retail reform in Texas, China Electric Power Newspaper(N), 2005-04-12(008).

[11] XU Zizhi, ZENG Ming. Analysis on Electricity Market Development in US and Its Inspiration to Electricity Market Construction in China[J], Power System Technology, 2011, 35(6):161-166.

[12] ZENG Ming. Enlightenment for China's electricity sales side reform based on the theory of Tirole, China Energy News, 2015-01-19(005). 